\title{
Pomegranate seed oil rich in conjugated linolenic acids reduces in vitro methane production
}

\author{
E. Maleki ${ }^{1}$, G.Y. Meng ${ }^{2,3 \#}$, M. Faseleh Jahromi ${ }^{3}$, R. Jorfi ${ }^{4}$, \\ A. Khoddami ${ }^{5}$ \& M. Ebrahimi ${ }^{2}$ \\ ${ }^{1}$ PhD Graduated of Animal Nutrition, Razi University, Kermanshah, Iran \\ ${ }^{2}$ Department of Veterinary Preclinical Sciences, Faculty of Veterinary Medicine, Universiti Putra Malaysia, 43400 UPM, \\ Serdang, Selangor, Malaysia \\ ${ }^{3}$ Institute of Tropical Agriculture, Universiti Putra Malaysia, 43400 UPM, Serdang, Selangor, Malaysia \\ ${ }^{4}$ Department of Food Science, Division of Sciences, University of Otago, PO Box 56, Dunedin, New Zealand \\ ${ }^{5}$ Faculty of Agriculture and Environment, Department of Plant and Food Sciences, University of Sydney, NSW, Australia
}

(Received 13 October 2015; Accepted 10 July 2016; First published online 1 October 2016)

\begin{abstract}
Copyright resides with the authors in terms of the Creative Commons Attribution 2.5 South African Licence.
See: http://creativecommons.org/licenses/by/2.5/za

Condition of use: The user may copy, distribute, transmit and adapt the work, but must recognise the authors and the South African Journal of Animal Science
\end{abstract}

\begin{abstract}
The objective of this study was to determine the effect of pomegranate (Punica granatum L.) seed oil (PSO) on gas and methane $\left(\mathrm{CH}_{4}\right)$ production, ruminal fermentation and microbial populations under in vitro conditions. Three treatments consisting of a control diet containing $10 \mathrm{mg}$ tallow (CON); the control diet with $5 \mathrm{mg}$ PSO $+5 \mathrm{mg}$ tallow (MPSO) and the control diet containing $10 \mathrm{mg}$ PSO (HPSO) were compared. Ten $\mathrm{mg}$ of the experimental fat/oil samples were inserted into a gas-tight $100 \mathrm{~mL}$ plastic syringe containing $30 \mathrm{~mL}$ of an incubation inoculum and $250 \mathrm{mg}$ of a basic substrate of a hay/concentrate $(1 / 1, \mathrm{w} / \mathrm{w})$ mixture. In vitro gas production was recorded over $0,2,4,6,8,10,12$ and $24 \mathrm{~h}$ of incubation. After 24 hours, incubation was stopped, and methane production, $\mathrm{pH}$, volatile fatty acids (VFAs) and microbial counts were measured in the inoculant. Gas production at 4, 6, 8, 10, 12 and $24 \mathrm{~h}$ incubation, metabolizable energy and in vitro organic matter disappearance increased linearly and quadratically as level of PSO increased. Furthermore, the 10 mg PSO (HPSO) decreased $\mathrm{CH}_{4}$ production by $21.0 \%$ compared with the control (CON) group. There were no significant differences in total and individual VFA concentrations between different levels of PSO, except for butyric acid. After $24 \mathrm{~h}$ of incubation, methanogenesis decreased in the HPSO compared with the MPSO and CON treatments. In addition, total bacteria and protozoa counts increased with rising PSO levels, while population methanogenesis declined significantly. These results suggested that PSO could reduce methane emissions, which might be beneficial to nutrient utilization and growth in ruminants.
\end{abstract}

Keywords: Gas production, methane, Punica granatum L, ruminal fermentation, rumen microbes

\# Corresponding author: gohyongmeng@gmail.com

\section{Introduction}

Methane produced during anaerobic fermentation in the rumen represents feed energy loss and contributes to the greenhouse effect in the environment. Therefore, reducing methane emission has been an important objective for ensuring the sustainability of ruminant production. Methane is produced normally during fermentation of feed by methanogenic archaea. The removal of protozoa could also reduce methane production because some populations of methanogens remain attached to protozoa (Hess et al., 2003).

Plant oil extracts that are rich in unsaturated fatty acids could alter rumen fermentation. The composition of fatty acids and the degree of saturation in plant oils are important factors that could affect the rumen fermentation process. Saturated fatty acids are less toxic than unsaturated ones, which may inhibit fermentation in the rumen more intensively (Jenkins, 1993). A reduction in methane production with the addition of unsaturated fatty acids has shown that these fatty acids could serve as electron acceptors during biohydrogenation in the rumen (Hegarty, 1999). Because long-chain and medium-chain fatty acids are less fermentable than short-chain fatty acids, they may reduce the percentage of $\mathrm{CH}_{4}$ produced in ruminants (Johnson \& Johnson, 1995). Fats and oils impair $\mathrm{CH}_{4}$ production. A number of mechanisms may be responsible for this effect, possibly as a direct consequence of medium-chain fatty acids or because longchain polyunsaturated fatty acids are toxic to protozoa, and because fats and oils cause general impairment of fermentation (Beauchemin et al., 2008; Hook et al., 2010). A reduction in hydrogen accumulation by the 
addition of unsaturated fat seems to be a promising procedure to reduce rumen $\mathrm{CH}_{4}$ production. However, because the effects of fats are dependent on their composition, when incubated with rumen fluid, only oleic (C18:1n-9), linoleic (C18:2n-6) and a-linolenic (C18:3n-3) acids reduced $\mathrm{CH}_{4}$ production (Wu et al., 2013; 2015). Mechanisms by which lipid supplementation lowers $\mathrm{CH}_{4}$ production have been proposed, including reduced fibre digestion, diminished dry matter intake, methanogenesis inhibition, inhibition of protozoa, and reduction of hydrogen that is used for fatty acid biohydrogenation.

Pomegranate (Punica granatum L.) is one of the oldest fruits and is from the punicaceae family. Around $55 \%-60 \%$ of pomegranate weight is edible, of which $75 \%-85 \%$ is juice and $15 \%-25 \%$ seed (Seeram et al., 2006). Seeds of all varieties of pomegranate are rich sources of oil. Pomegranate seeds contain 6.6\% - 24\% oil (Khodami et al., 2014). The oil consists of palmitic acid (C16:0) and stearic acid (C18:0), both saturated fatty acids, oleic acid (C18:1), a monounsaturated fatty acid, linoleic acid (C18:2), and an isomer of linolenic acid or conjugated linolenic acid (C18:3), called punicic acid (9-cis,11-trans,13-cis or trichosanic acid), both polyunsaturated fatty acids (Khoddami \& Roberts, 2015). Punicic acid (31\% - 86\%) is the dominant fatty acid in pomegranate oil, followed by linoleic acid $(0.7 \%-24.4 \%)$ and oleic acid $(0.4 \%$ 17.4\%) (Khodami et al., 2014; Khoddami \& Roberts, 2015). A study of four cultivars of Iranian pomegranate seed oil (PSO) showed that $7.7 \%-8.1 \%$ of the fatty acids are saturated and $91.8 \%-92.1 \%$ unsaturated (Dadashi et al., 2013). Thus, the researchers hypothesized that PSO, which is rich in punicic acid, would alter the methanogenesis count without detrimental effects on rumen fermentation. The literature review showed that research has not been conducted on the effects of PSO on the parameters of rumen fermentation. Thus, the aim of this study was to determine the impact of PSO on in vitro gas production, rumen fermentation and microbial accounts in goats.

\section{Materials and Methods}

Pomegranate seed oil was extracted in a laboratory from dried pomegranate seeds using hexane as a solvent. The fatty acid profile of PSO was identified with gas liquid chromatography. The results are presented in Table 1.

Table 1 Fatty acid composition (\%) of pomegranate seed oil

\begin{tabular}{lc}
\hline Fatty acid & Amount (\%) \\
\hline C14:0 & 0.42 \\
C16:0 (palmitic acid) & 4.85 \\
C16:1 (palmitoleic acid) & 0.14 \\
C18:0 (stearic acid) & 3.86 \\
C18:1 n-9 (oleic acid) & 10.40 \\
C18:2n-6 (linoleic acid) & 7.38 \\
C18:3n-3 (a-linolenic acid) & 0.22 \\
CLNA & 72.56 \\
C20:0 (arachidic acid) & 0.17 \\
SFA & 9.13 \\
MUFA & 10.54 \\
PUFA & 80.16 \\
n-3PUFA & 72.78 \\
n-6PUFA & 7.38 \\
n-6/n-3 & 0.10 \\
\hline
\end{tabular}

SFA: saturated fatty acids (sum of C14:0+C16:0+C18:0+C20:0); MUFA: monounsaturated fatty acids (sum of $\mathrm{C} 16: 1+\mathrm{C} 18: 1 \mathrm{n}-9$ ); PUFA: polyunsaturated fatty acids (sum of C18:2n-6+ C18:3n-3+ CLNA); CLNA: conjugated linolenic acid.

Rumen fluid was collected from four rumen-fistulated (Bar-Diamond, Parma, ID, USA) Kacang crossbred male goats, weighing $35.41 \pm 0.84 \mathrm{~kg}$, which received a diet of $50 \%$ alfalfa hay and $50 \%$ goat 
concentrate (WM) twice daily at 08:00 and 17:00 for three months. The concentrate consisted of corn (25.4\%), soybean meal (19\%), palm kernel cake (35.9\%), rice bran (11.7\%), palm kernel oil (5\%), ammonium chloride (1\%) and a vitamin and mineral mixture (1\%). The rumen fluid from the goats was mixed on a volume basis, and filtered through four layers of cheesecloth. The incubation inoculum was prepared by diluting the rumen fluid with a buffer solution according to Fievez et al. (2005) in a $1: 4(\mathrm{v} / \mathrm{v})$ ratio. Mixed inoculums were stirred in a water bath at $39{ }^{\circ} \mathrm{C}$ with purging $\mathrm{CO}_{2}$ until use (10 - 15 min later). The three treatments were CON (control diet, without PSO, adjusted with $10 \mathrm{mg}$ tallow), MPSO (control diet with $5 \mathrm{mg}$ PSO, adjusted with $5 \mathrm{mg}$ tallow) and HPSO (control diet with $10 \mathrm{mg} \mathrm{PSO}$ ). As substrate ca. $250 \mathrm{mg}$ (1 mm ground) of a mixture of alfalfa hay and concentrate $(1 / 1, \mathrm{w} / \mathrm{w})$ was placed in gas-tight $100 \mathrm{~mL}$ plastic syringes, and $30 \mathrm{~mL}$ of the incubation inoculum was added. Then samples containing $10 \mathrm{mg}$ tallow, $5 \mathrm{mg}$ PSO + $5 \mathrm{mg}$ tallow, and $10 \mathrm{mg}$ PSO were injected into the syringes of the CON, MPSO and HPSO treatments, respectively. All air was expelled from the syringes, after which their tips were closed. The syringes were placed in an incubator at $39^{\circ} \mathrm{C}$ for $24 \mathrm{~h}$. Volumes of the gas produced were determined after $0,2,4,6,8,10,12$ and $24 \mathrm{~h}$ incubation, and syringes were shaken carefully to ensure complete mixing of the contents. The experiment was repeated as three runs on three separate days with six replicates to estimate gas production.

Metabolizable energy (ME, MJ/kg DM) and in vitro organic matter disappearance (IVOMD) were estimated according to Menke et al. (1979) as:

$$
\begin{aligned}
& \mathrm{OMD}(\mathrm{g} / \mathrm{kg} \mathrm{OM})=148.8+8.89 \mathrm{GP}+4.5 \mathrm{CP}+0.651 \mathrm{XA} \\
& \mathrm{ME}(\mathrm{MJ} \mathrm{kg} / \mathrm{DM})=2.20+0.136 \mathrm{GP}+0.057 \mathrm{CP}
\end{aligned}
$$

where $\mathrm{OMD}$ is $\mathrm{OM}$ disappearance

$\mathrm{ME}$ is metabolizable energy

$\mathrm{CP}$ is crude protein in $\mathrm{g} / 100 \mathrm{~g} \mathrm{DM}$

$X A$ is ash in $\mathrm{g} / 100 \mathrm{~g} \mathrm{DM}$

GP is the net gas production $(\mathrm{mL})$ per $200 \mathrm{mg}$ sample.

Table 2 Chemical composition of substrate used for in vitro incubation

\begin{tabular}{lr}
\hline Chemical composition & $\mathbf{g} / \mathbf{k g}$ \\
\hline Dry matter & 911.0 \\
Organic matter & 928.5 \\
Crude protein & 185.0 \\
Ether extract & 53.7 \\
Neutral detergent fibre & 375.2 \\
Acid detergent fibre & 225.0 \\
\hline
\end{tabular}

After $24 \mathrm{~h}$ of incubation, methane production was measured by injecting $1 \mathrm{~mL}$ headspace gas from each of the syringes into a gas-liquid chromatograph (Agilent 5890 Series gas chromatograph, Wilmington, Delaware, USA) equipped with an FID detector. Separation was achieved with an HP-Plot Q column (30 $\mathrm{m} \times$ $0.53 \mathrm{~mm} \times 40 \mathrm{~m}$ ) (Agilent Technologies, Wilmington, Delaware, USA) with nitrogen (99.9\% purity) (DomnickHunter generator, Domnick-Hunter, Leicester, UK) as the carrier gas at a flow rate of $3.5 \mathrm{~mL} / \mathrm{min}$. An isothermal oven temperature of $50{ }^{\circ} \mathrm{C}$ was adopted in the separation. Calibration was completed using standard methane prepared by Scotty Specialty Gases (Supelco, Bellefonte, Philadelphia, USA). All the procedures were repeated three times. The $\mathrm{pH}$ of the contents of the syringes was determined with a $\mathrm{pH}$ electrode (Mettler-Toledo Ltd., Salford, England).

The volatile fatty acid (VFA) content of the incubated rumen fluid was determined with gas chromatography. The incubated rumen fluid was fixed with 25\% metaphosphoric acid, centrifuged at 3000 $\mathrm{rpm}$, and the supernatant collected. The supernatant $(0.5 \mathrm{~mL})$ was added to an equal volume of $20 \mathrm{mM}$ methyl n-valeric acid (Sigma Chemical Co., St. Louis, Missouri, USA). Separation was done on a Quadrex 007 Series (Quadrex Corporation, New Haven, CT 06525 USA) bonded phase fused silica capillary column (15 m, $0.32 \mathrm{~mm} \mathrm{ID,} 0.25 \mu \mathrm{m}$ film thickness) in an Agilent 7890A gas-liquid chromatograph (Agilent 
Technologies, Palo Alto, Calif, USA) equipped with a flame ionization detector. The injector/detector temperature was programmed at $220 / 230^{\circ} \mathrm{C}$, respectively. The column temperature was set in the range of $70-150^{\circ} \mathrm{C}$ with temperature programming at the rate of $7^{\circ} \mathrm{C} / \mathrm{min}$ increments to facilitate optimal separation. Peaks were identified by comparison with authentic standards of acetic, propionic, butyric, isobutyric, valeric, isovaleric and 4-methyl-n-valeric acids (Sigma, St. Louis, Mo., USA), as described by Ebrahimi et al. (2014).

After $24 \mathrm{~h}$ of incubation, $1 \mathrm{~mL}$ rumen fluid from each of the syringes was used for DNA extraction. Total DNA was extracted from $0.4 \mathrm{~mL}$ homogenized rumen fluid using the QIAamp DNA Stool Mini Kit (Qiagen Inc., Valencia, Calif.) according to the manufacturer's protocol. The extracted DNA was stored at $-20^{\circ} \mathrm{C}$ until used. Plasmid DNA from each group of microorganisms used for the preparation of a standard curve and the purity and concentration of plasmid DNA in each sample were measured with a spectrophotometer and the number of copies of a template DNA per $\mathrm{mL}$ of elution buffer were calculated according to the following formula, which is available online at the University of Rhode Island Genomics and Sequencing Centre (www.uri.edu/research/gsc/resources/cndna.html).

$$
\text { Number of copies }=\frac{\text { Amount of DNA }\left(\mu \frac{\mathrm{g}}{\mathrm{mL}}\right) \times 6.022 \times 10^{23}}{\text { Length }(\mathrm{bp}) \times 10^{9} \times 650}
$$

Standard curves were constructed using CT values, which were obtained from a serial dilution of plasmid DNA from each bacterial group.

Primers that were used to quantify the populations of groups of microorganisms, were adapted from Ebrahimi (2012):

Table 3 Microorganism sequences of primers

\begin{tabular}{lc}
\hline Microorganism & Sequence $\mathbf{5}^{\prime} \mathbf{-} \mathbf{3}^{\prime}$ \\
\hline Total bacteria $\mathrm{F}^{1}$ & CGGCAACGAGCGCAACCC \\
Total bacteria $\mathrm{R}^{2}$ & CCATTGTAGCACGTGTGTAGCC \\
Methanobacteriales F (MBT857F) & CGWAGGGAAGCTGTTAAGT \\
Methanobacteriales R (MBT1196R) & TACCGTCGTCCACTCCTT \\
Total protozoa R & GCTTTCGWTGGTAGTGTATT \\
Total protozoa F & CTTGCCCTCYAATCGTWCT \\
& \\
\hline${ }^{1}$ forward ${ }^{2}$ reverse &
\end{tabular}

${ }^{1}$ forward, ${ }^{2}$ reverse.

Rumen fermentation parameters and rumen microbes were analysed by one-way ANOVA, using the MIXED procedure of the SAS software package, version 9.1 (SAS, 2003). The following model was used: $Y i j=I+D i+S j+$ eij, where Yij represents an observation; I is the overall mean; $D i$ is the effect of the treatment $(i=1,2,3) ; \mathrm{Sj}$ is the replicate, and eij is the residual error. Means were separated using the PDIFF option of the least squares means statement of the MIXED procedure. Linear and quadratic contrasts were used to determine the effects of increasing amounts of PSO on the response variables. Data were checked for normality using the UNIVARIATE procedure of SAS software (SAS, 2003). The results are presented as means \pm standard error of the mean.

\section{Results}

The results of in vitro gas production are presented in Table 4. Methane production is illustrated graphically in Figure 1 . The results showed that the gas produced $(\mathrm{mL} / 250 \mathrm{mg} \mathrm{DM})$ after $2 \mathrm{~h}$ incubation was not affected by PSO $(P>0.05)$. However, gas production at $4,6,8,10,12$ and $24 \mathrm{~h}$ incubation increased linearly and quadratically with cumulative PSO $(P<0.05)$. In vitro organic matter disappearance and metabolizable energy were affected by PSO. Metabolizable energy (MJ/kg DM) and IVOMD ( $/ \mathrm{kg} \mathrm{OM}$ ) increased linearly and quadratically $(P<0.05)$ with accumulative PSO. Methane production of HPSO was higher $(P<0.05)$ than CON, but not significantly different from the MPSO $(P>0.05)$. 
Table 4 Effect of pomegranate seed oil on in vitro gas production (mL/250 mg DM) after 24 hours' incubation

\begin{tabular}{lccccccc}
\hline $\begin{array}{l}\text { Incubation } \\
\text { time(h) }\end{array}$ & \multicolumn{3}{c}{ Treatments } & & \multicolumn{2}{c}{$P$-values } \\
\cline { 2 - 3 } & CON & MPSO & HPSO & & Linear & Quadratic \\
\hline 2 & 4.33 & 3.33 & 4.00 & 0.484 & 0.792 & 0.448 \\
4 & 6.17 & 4.33 & 9.50 & 0.642 & 0.004 & 0.001 \\
6 & 9.33 & 6.17 & 13.67 & 0.855 & 0.001 & $<0.001$ \\
8 & 12.50 & 9.17 & 18.50 & 1.03 & $<0.001$ & $<0.001$ \\
10 & 16.17 & 13.00 & 23.67 & 1.20 & $<0.001$ & $<0.001$ \\
12 & 18.67 & 16.0 & 26.67 & 1.27 & $<0.001$ & $<0.001$ \\
24 & 28.17 & 25.0 & 38.67 & 1.78 & 0.002 & 0.004 \\
ME & 6.32 & 5.97 & 7.46 & 0.194 & 0.002 & 0.004 \\
IVOMD & 436.41 & 413.88 & 511.09 & 12.68 & 0.002 & 0.004
\end{tabular}

CON: control (10 mg tallow); MPSO: medium pomegranate seed oil (5 mg tallow, $5 \mathrm{mg}$ PSO);

HPSO: high pomegranate seed oil (10 mg PSO) after $24 \mathrm{~h}$ in vitro incubation;

ME: metabolizable energy (MJ/kg DM); IVOMD: in vitro organic matter disappearance ( $\mathrm{g} / \mathrm{kg} \mathrm{OM})$.

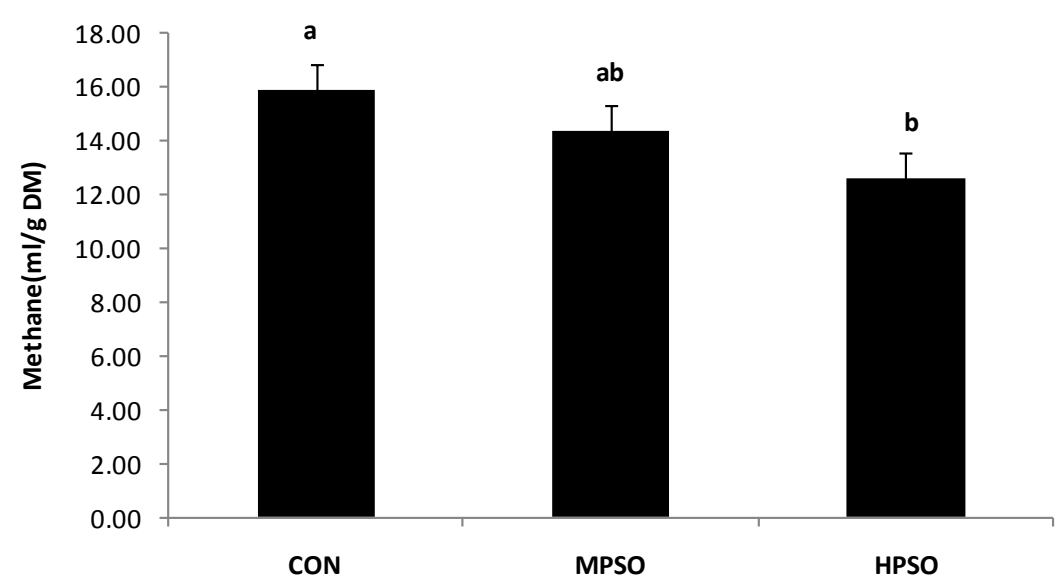

Figure 1 Methane production in experimental treatments.

CON: control (10 mg tallow); MPSO: medium pomegranate seed oil (5 mg tallow, $5 \mathrm{mg}$ PSO), HPSO: high pomegranate seed oil (10 mg PSO) after $24 \mathrm{~h}$ in vitro incubation. Data presented as means with pooled standard error of the mean. Mean values sharing no common superscript are significantly different at $P<0.05$.

The results of VFA and $\mathrm{pH}$ are presented in Table 5. Total VFA was not affected by PSO levels $(P$ $>0.05)$. Acetate, propionate, valerate, iso-valerate, iso-butyrate and acetate to propionate ratios were not affected $(P>0.05)$ by PSO treatments, while butyrate concentration decreased linearly and quadratically $(P$ $<0.05)$ with increasing PSO. The $\mathrm{pH}(7.18,7.16$ and 7.26$)$ for the CON, MPSO, and HPSO diets, respectively, was not affected $(P>0.05)$ by oil supplements after $24 \mathrm{~h}$ incubation.

The results of the bacteria and protozoa count in the rumen are presented in Table 6. However, total bacteria numbers increased $(P<0.001)$ linearly, whereas methanogenesis decreased $(P<0.001)$ linearly with raised PSO. However, they did not show a quadratic effect by increasing the POS in the diet. The total number of protozoa showed linear and quadratic increases $(P<0.001)$ with augmenting the dietary levels of PSO. 
Table 5 Effect of pomegranate seed oil on total and individual volatile fatty acid (VFA) production (mol/100 $\mathrm{mol}$ ) and $\mathrm{pH}$ after $24 \mathrm{~h}$ incubation

\begin{tabular}{|c|c|c|c|c|c|c|}
\hline & \multicolumn{3}{|c|}{ Treatments } & \multirow{2}{*}{ SEM } & \multicolumn{2}{|c|}{$P$-values } \\
\hline & CON & MPSO & HPSO & & Linear & Quadratic \\
\hline Total VFA (mmol/g DM) & 9.68 & 9.72 & 10.01 & 0.273 & 0.950 & 0.617 \\
\hline \multicolumn{7}{|c|}{ Individual VFA (mol/100 mol) } \\
\hline Acetate & 59.36 & 59.72 & 61.21 & 0.548 & 0.792 & 0.170 \\
\hline Propionate & 24.99 & 25.50 & 25.60 & 0.442 & 0.662 & 0.719 \\
\hline Isobutyrate & 1.91 & 1.73 & 1.73 & 0.106 & 0.516 & 0.727 \\
\hline Butyrate & 10.19 & 9.12 & 8.48 & 0.232 & 0.019 & 0.005 \\
\hline Isovalerate & 1.68 & 2.09 & 1.15 & 0.266 & 0.543 & 0.212 \\
\hline Valerate & 1.86 & 1.84 & 1.82 & 0.120 & 0.958 & 0.894 \\
\hline Acetate : propionate & 2.39 & 2.37 & 2.40 & 0.054 & 0.926 & 0.904 \\
\hline $\mathrm{pH}$ & 7.18 & 7.16 & 7.26 & 0.037 & 0.417 & 0.490 \\
\hline
\end{tabular}

CON: control (10 mg tallow), MPSO: medium pomegranate seed oil (PSO) (5 mg tallow, 5 mg PSO);

HPSO: high pomegranate seed oil (10 mg PSO) after $24 \mathrm{~h}$ in vitro incubation.

Table 6 Effects of pomegranate seed oil on rumen bacteria and protozoa concentration $\left(\log _{10}\right.$ copy no/L) of rumen fluid

\begin{tabular}{|c|c|c|c|c|c|c|}
\hline \multirow{2}{*}{$\begin{array}{l}\log _{10} \text { copy no/L of } \\
\text { rumen fluid }\end{array}$} & \multicolumn{3}{|c|}{ Treatments } & \multirow{2}{*}{ SEM } & \multicolumn{2}{|c|}{$P$-values } \\
\hline & CON & MPSO & HPSO & & Linear & Quadratic \\
\hline Total bacteria & 11.96 & 12.23 & 12.69 & 0.057 & 0.0001 & 0.122 \\
\hline Total methanogenesis & 7.90 & 7.76 & 7.43 & 0.051 & 0.0001 & 0.268 \\
\hline Total protozoa & 6.25 & 6.33 & 7.47 & 0.101 & 0.0001 & 0.0001 \\
\hline
\end{tabular}

CON: control (10 mg tallow), MPSO: medium pomegranate seed oil (PSO) (5 mg tallow, 5 mg PSO);

HPSO: high pomegranate seed oil (10 mg PSO) after $24 \mathrm{~h}$ in vitro incubation.

\section{Discussion}

In the current study, gas production at the various incubation times increased with higher levels of PSO, except at $2 \mathrm{~h}$. The rise in asymptotic gas production indicated better nutrient availability for rumen microorganisms (Mahala \& Fadel Elseed, 2007). However, the current results indicated that in vitro gas production of mixed $50 \%$ forage and $50 \%$ concentrate substrate increased with $\mathrm{PSO}$, which is rich in punicic acid. In previous studies, Lee et al. (2001) showed the effects of long chain fatty acids on in vitro gas production by rumen anaerobic fungus and confirmed that in vitro gas production of filter paper was significantly increased by the addition of stearic, oleic and linoleic acids, but significantly reduced by the addition of linolenic acid. However, Wu et al. (2013) found that in vitro gas production of Leymus chinensis meal at $48 \mathrm{~h}$ using mixed rumen fluids of goats was decreased by the addition of oleic and linoleic acids. Similarly, in vitro gas production of mixed fine-ground corn and soybean meal at $4 \mathrm{~h}$ using mixed rumen fluids of steers decreased when adding $4 \%$ flaxseed oil (Quinn \& Loe, 2008). In contrast, in another study Patra \& Yu (2012) reported that coconut oil increased total gas production linearly. The variation in gas production between the results of the current study and previous studies might be due to different substrates, dosages and types of supplemented long-chain fatty acids and rumen microbes. In this study, methane production decreased quadratically with PSO supplementation. This may be because the high degree of unsaturation of PSO made it toxic to methanogens (Prins et al., 1972) and resulted in a strong decrease of a methanogenesis population. PSO is highly unsaturated, which could explain the mitigation of methane emission with PSO. Current researches have shown that methane production could be reduced with the 
addition of oils rich in unsaturated fatty acids, such as soybean oil, sunflower seed oil, coconut oil and fish oil, which significantly decrease methane production owing to their biohydrogenation (Patra \& Yu, 2012) and their toxic effects on methanogen bacteria (Benchar et al., 2014). A study by Lunsin et al. (2012) demonstrated that rice bran oil, which consists of high levels of oleic and linoleic acids, reduced methane production in lactating dairy cows. Patra \& Yu (2012) indicated a quadratic decrease in methane concentration with supplementation of fish and coconut oils after in vitro gas production incubation. Similarly, Wu et al. (2015) noted that methane production decreased in response to linoleic acid supplementation at 12,24 and $48 \mathrm{~h}$ in vitro. All these studies are in line with the current study, which suggests that methane emissions could be reduced owing to the direct effect of PSO on methanogenesis.

The estimated ME concentration (MJ/kg DM) of treatments was calculated from the amount of gas produced at 24 hours' incubation with a supplementary analysis of crude protein. The estimated ME (MJ/kg $\mathrm{DM})$ and IVOMD (g/kg DM) were higher in the HPSO treatment compared with MPSO and the control.

Volatile fatty acids are major sources of metabolizable energy in ruminants (Van Soest, 1982). Reduction in VFA production would be nutritionally unfavourable for the animal. However, total VFA concentration (9.68, 9.72 and $10.01 \mathrm{mmol} / \mathrm{g} \mathrm{DM})$ for the CON, MPSO and HPSO treatments, respectively, was not affected $(P>0.05)$, which suggests that this oil did not affect diet volatile acids. In a similar study, Ishlak et al. (2014) reported that supplementation of soybean oil, PSO and blackberry oil in a continuous culture system had no influence on total VFA. In another study, it was reported that fish and coconut oils had no impact on total VFA concentration (Patra \& Yu, 2012). Butyrate decreased with PSO supplementation, confirming the results of Beauchemin et al. (2009), which indicated that butyrate level decreased with oilseed supplementation. The rise in molar proportions of butyrate may be the result of increased hydrogen in the rumen, which could be utilized by methanogenic bacteria to produce $\mathrm{CH}_{4}$ (Moss et al., 2000). Therefore, reduced molar proportions of butyrate would be in agreement with the linear reduction in $\mathrm{CH}_{4}$ formation with supplementation of PSO.

Similarly, the rumen fluid-incubated $\mathrm{pH}$ observed in this study was not influenced by diet, and was ideal for optimal rumen digestion and fermentation (Ørskov 1994). This observation is consistent with the results of Vargas et al. (2011), who observed that the addition of various vegetable oils (olive, sunflower, or flaxseed oils) did not alter $\mathrm{pH}$ concentration in vitro. The absence of detrimental effects of PSO could be owing to the nature of the oil. It has been reported that oil enhancement has minimal effects on rumen fermentation, despite their unsaturated nature (Palmquist \& Conrad, 1980; Palmquist, 1991; Jenkins, 1993). Also, the moderate forage to concentrate ratio (50:50) employed in this study could be responsible for the lack of detrimental effects of the test oil on fermentation and microbial accounts.

In the current study, PSO, which is rich in punicic acid, had a positive effect on microbial growth. In addition, it increased total bacteria and protozoa. Other researchers have shown that flaxseed oil, which is rich in linolenic acid, did not affect the number of protozoa in the rumen fluid of cows (Doreau et al., 2009; Benchar et al., 2014). Ueda et al. (2003) reported that 3\% flaxseed oil supplementation to a concentrate-rich diet (65\%) fed to dairy cows did not alter the number of total protozoa. However, when $3 \%$ flaxseed oil was added to a forage-rich diet (65\%), the number of protozoa did not change (Ueda et al., 2003). Based on these results, it appears that oil supplementation and basal diet cause shifts in the protozoal population. The reported influence of oils on rumen protozoa varies among studies, depending on the concentration, type, and fatty acid composition of the oil, as well as the nutrient composition of the diet (Ueda et al., 2003; Benchar et al., 2014). Supplementation with PSO resulted in linear decreases of methanogenesis. This is supported by Kim et al. (2008), who found that lipids inhibited methanogenesis owing to the toxicity of longchain fatty acids to methanogenic bacteria (Henderson, 1973).

\section{Conclusions}

Pomegranate seed oil increased total bacterial and protozoa populations and decreased methanogenesis, which would be reflected positively in the form of decreased methane. PSO supplementation did not have negative effects on in vitro fermentation, although fermentation shifted within the whole incubation period and increased gas production.

\section{Acknowledgments}

The authors would like to thank the Faculty of Veterinary Medicine, Universiti Putra Malaysia.

\section{Authors' Contribution}

EM, ME, GYM, RJ, MFJ and AK contributed to the idea, design, and execution of the study. EM and ME performed the fatty acid analysis, while MFJ and EM contributed for the microbial work. ME and EM were responsible for the statistical analysis. All authors contributed equally to the write-up of the final manuscript. 


\section{Conflict of Interest Declaration}

The authors declare that there is no conflict of interests regarding the publication of this article.

\section{References}

Beauchemin, K.A., Kreuzer, M., O'Mara, F. \& McAllister, T.A., 2008. Nutritional management for enteric methane abatement: a review. Aust. J. Exp. Agric. 48, 21-27.

Beauchemin, K.A., McGinn, S.M., Benchaar, C. \& Holtshausen, L., 2009. Crushed sunflower, flax, or canola seeds in lactating dairy cow diets: Effects on methane production, rumen fermentation, and milk production. J. Dairy Sci. 92, 2118-2127.

Benchar, C., McAllister, T.A., Petit, H.V. \& Chouinard, P.Y., 2014. Whole flax seed and flax oil supplementation of dairy cows fed high-forage or high-concentrate diets: Effects on digestion, ruminal fermentation characteristics, protozoal populations and milk fatty acid profile. Anim. Feed. Sci. Technol. 198, 117-129.

Dadashi, S., Mousazadeh, M., Emam-Djomeh, Z. \& Mousavi, M., 2013. Pomegranate (Punica granatum L.) seed: A comparative study on biochemical composition and oil physicochemical characteristics biochemical composition of pomegranate seed oil. Int. J. Adv. Biol. Biom. Res. 1, 351-363.

Doreau, M., Aurousseau, E. \& Martin, C., 2009. Effects of linseed lipids fed as rolled seeds, extruded seeds or oil on organic matter and crude protein digestion in cows. Anim. Feed Sci. Technol. 150, 187-196.

Ebrahimi, M., 2012. Production of omega-3 polyunsaturated fatty acid- enriched chevon using treated oil palm (Elaeis guineensis jacq.) frond silage. PhD thesis, Universiti Putra Malaysia, Serdang, Selangor, Malaysia.

Ebrahimi, M., Rajion, M.A., Goh, Y.M., Farjam, A.S., Sazili, A.Q. \& Schonewille, J.T., 2014. The effects of adding lactic acid bacteria and cellulase in oil palm (Elais guineensis Jacq.) frond silages on fermentation quality, chemical composition and in vitro digestibility. Italian J. Anim. Sci. 13, 557-562.

Fievez, V., Babayemi, O.J. \& Demeyer, D., 2005. Estimation of direct and indirect gas production in syringes: A tool to estimate short chain fatty acid production that requires minimal laboratory facilities. Anim. Feed Sci. Technol. 123, 197-10.

Hegarty, R.S., 1999. Reducing rumen methane emission through elimination of protozoa. Aust. J. Agric. Res. 50, 1321-1327.

Hess, H.D., Kreuzer, M., Diaz, T.E., Lascano, C.E., Carulla, J.E. \& Soliva, C.R., 2003. Saponin rich tropical fruits affect fermentation and methanogenesis in faunated and defaunated fluid. Anim. Feed Sci. Technol. 109, 79-94.

Hook, S.E., Wright, A.D.G. \& McBride, B.W., 2010. Methanogens: methane producers of the rumen and mitigation strategies. Archaea 2010, 1-10.

Ishlak, A., AbuGhazaleh, A.A. \& Günal, M., 2014. Short communication: Effect of blackberry and pomegranate oils on vaccenic acid formation in a single-flow continuous culture fermentation system. J. Dairy Sci. 97, 1067-107.

Jenkins, T.C., 1993. Lipid metabolism in the rumen. J. Dairy Sci. 76, 3851-3863.

Johnson, K.A. \& Johnson, D.E., 1995. Methane emissions from cattle. J. Anim. Sci. 73, 2483-2492.

Khoddami, A. \& Roberts, T., 2015. Pomegranate oil as a valuable pharmaceutical and nutraceutical. Lipid Technol. 27 (2), 40-42.

Khodami, A., Bin Che Man, Y. \& Roberts, T., 2014. Physico-chemical properties and fatty acid profile of seed oils from pomegranate (Punica granatum L.) extracted by cold pressing. Eur. J. Lipid Sci. Technol. 116, 553-562.

Kim, E.J., Huws, S.A., Lee, M.R.F., Wood, J.D., Muetzel, S.M., Wallace, R.J. \& Scollan, N.D., 2008. Fish oil increases the duodenal flow of long chain polyunsaturated fatty acids and trans-11 18:1 and decreases 18:0 in steers via changes in the rumen bacterial community. J. Nutr. 138, 889-896.

Lee, S., Ha, S. \& Cheng, K.J., 2001. Effects of LCFA on the gas production, cellulose digestion and cellulase activities by the rumen anaerobic fungus, Neocallimastix frontalis RE1. Asian-Austral. J. Anim. Sci. 14, 1110-1117.

Lunsin, R., Wanapat, M., Yuangklang, C. \& Rowlinson, P., 2012. Effect of rice bran oil supplementation on rumen fermentation, milk yield and milk composition in lactating dairy cows. Livest. Sci. 145, 167-173.

Mahala, A.G. \& Fadel Elseed, A.M.A., 2007. Chemical composition and in vitro gas production characteristics of six fodder trees, leaves and seeds. Res. J. Agric. Biol. Sci. 3, 983-986.

Menke, K.H., Raab, L., Salewski, A., Steingass, H., Fritz, D. \& Schneider, W., 1979. The estimation of the digestibility and metabolizable energy content of ruminant feedstuffs from the gas production when they are incubated with rumen liquor in vitro. J. Dairy Sci. 92, 217-222.

Moss, A.R., Jouany, J. \& Newbold, J., 2000. Methane production by ruminants: Its contribution to global warming. Ann Zootech. 49, 231-253.

Ørskov, E., 1994. Recent advances in understanding of microbial transformation in ruminants. Livest. Prod. Sci. 39, 53-60.

Palmquist, D., 1991. Influence of source and amount of dietary fat on digestibility in lactating cows. J. Dairy Sci. 74, 1354-1360.

Palmquist, D. \& Conrad, H., 1980. High fat rations for dairy cows. Tallow and hydrolyzed blended fat at two intakes. J. Dairy Sci. 63, 391-395.

Patra, A.K. \& Yu, Z., 2012. Effects of coconut and fish oils on ruminal methanogenesis, fermentation, and abundance and diversity of microbial populations in vitro. J. Dairy Sci. 96, 1782-1792.

Prins, R.A., Van Nevel, C.J. \& Demeyer, D.I., 1972. Pure culture studies of inhibitors for methanogenic bacteria. Ant. van Leeuwen 38, 281-287. 
Quinn, M.J., Loe, E.R., Depenbusch, B.E., Higgins, J.J. \& Drouillard, J.S., 2008. The effects of flaxseed oil and derivatives on in vitro gas production, performance, carcass characteristics, and meat quality of finishing steers. Prof. Anim. Sci. 24, 161-168.

SAS, 2003. Statistical Analysis Systems user's guide: Statistics, Version 9.1 edition. SAS Inst., Inc., Cary, N.C., USA.

Seeram, N.P., Zhang, Y., Reed, J.D., Krueger, C.G. \& Vaya, J., 2006. Pomegranate phytochemicals. In: Pomegranates: Ancient roots to modern medicine. Eds: Boca Raton, CRC Press. pp. 3-29.

Ueda, K., Ferlay, A., Chabrot, J., Loor, J.J., Chilliard, Y. \& Doreau, M., 2003. Effect of linseed oil supplementation on ruminal digestion in dairy cows fed diets with different forage: concentrate ratios. J. Dairy Sci. 86, 3999-4007.

Van Soest, P.J., 1982. Nutritional Ecology of the Ruminant. Cornell University Press, Corvallis, OR, USA. pp. $253-280$.

Vargas, J.E., Andrés, S., Yáñez Ruiz, D.R. \& López, S., 2011. Challenging strategies to promote the sheep and goat sector in the current global context, ciheam/CSIC/Universidad de León/FAO, Zaragoza. pp. 163-168.

Wu, D., Tang, S., He, Z., Odongo, E.D., Tan, Z., Han, X., Zhou, C., Kang, J. \& Wang, M., 2013. Oleic and linoleic acids alter fermentation characteristics, methane and fatty acid isomers production during in vitro incubation with mixed ruminal microbes. J. Food. Agric. Environ. 11, 464-469.

Wu, D., Xu, L., Zhixiong, S.H., Zhiliang, H., Han, T.X., Zhou, C., Kang, J. \& Wang, M., 2015. Supplementation of increasing amounts of linoleic acid to leymus chinensis decreases methane production and improves fatty acid composition in vitro. Eur. J. Lipid Sci. Technol. 117, 945-953. 